\title{
KOMPARASI PENGUJIAN MUTU BETON DENGAN MENGGUNAKAN METODE SNI 03-4430-1997 DAN SNI 1974-1990 DALAM KEGIATAN PENGABDIAN MASYARAKAT DI LABORATORIUM STRUKTUR DAN BAHAN KONSTRUKSI UNIVERSITAS BRAWIJAYA
}

\author{
Sugeng Hendik $\mathbf{P}^{1)}$, Dhino Teguh $\mathbf{P}^{2)}$ \\ ${ }^{1)}$ Pranata Laboratorium Pendidikan, Laboratorium Struktur dan Bahan Konstruksi, \\ Jurusan Teknik Sipil, Fakultas Teknik, Universitas Brawijaya Malang \\ ${ }^{2)}$ Pranata Laboratorium Pendidikan ,Laboratorium Struktur dan Bahan Konstruksi, Jurusan \\ Teknik Sipil , Fakultas Teknik, Universitas Brawijaya Malang
}

\begin{abstract}
ABSTRAK
Penelitian ini adalah penelitian eksperimental yang dilakukan di laboratorium, untuk mengetahui perbandingan pengukuran kekuatan beton pada kegiatan pengabdian masyarakat di Laboratorium Struktur dan Bahan Konstruksi Fakultas Teknik Universitas Brawijaya. Pengukuran kekuatan beton bisa menggunakan metode merusak dan tidak merusak. Tujuan dari penelitian ini untuk mendapatkan konstanta pengali nilai hasil pengujian Hammer Test, sehingga hasilnya bisa mendekati hasil pengujian dengan menggunakan Mesin Uji Tekan. Adapun variabel penelitian adalah jenis sampel dan metode pengujian. Jumlah sampel untuk setiap umur beton adalah 20 silinder dan 20 kubus, sehingga total adalah 40 buah sampel beton, setelah itu dilakukan pengujian kekuatan dengan menggunakan metode non destruktif dan dengan bahan yang sama dilakukan pengujian kuat tekan dengan metode destruktif. Hasil penelitian ini menunjukkan bahwa pengujian dengan menggunakan hammer test nilainya lebih rendah dibandingkan dengan pengujian dengan Compression Machine dan didapatkannya konstanta pengali sebesar 0,88. Sehingga dengan menggunakan nilai hasil pengujian dengan alat hammer test estimasi kekuatan beton bisa diukur terlebih dahulu tanpa menggunakan metode Destruktif
\end{abstract}

Kata-kata kunci : pengujian merusak dan tidak merusak, mesin uji tekan, uji kekerasan

\section{ABSTRACT}

This research is experimental research conducted at laboratory, to find the comparison of strength measurement of concrete in Community Service Activities at Laboratory of Structures and Construction Materials can use the method of destructive and non-destructive. The main purpose of this research is to get the value of multiplier constant from the test result of Hammer Test, so the result can come near to the test result by using Compression Machine. The research variable are; sample type (cube of $15 \times 15$ and cylinder of $15 \times 30$ ), testing method (hammer test vs Universal testing machine). The number of concrete cylinder sample $(\varnothing 15 \mathrm{~cm} \times 30 \mathrm{~cm})$ for each concrete age is 20 of cylinder and 20 of cube, so the total is 40 pcs of concrete sample, after that, compressive strength test is performed by using method of non-destructive and by the same materials, compressive strength test is performed by using method of destructive. The result of this research is prove that value test by using Hammer Test is lower that using Compression Machine and the obtained of multiplier constant is 0.88 . So by using value of test result with hammer test, estimation of concrete strength can be measured in advance without using method of destructive.

Keywords : destructive test, non-destructive test, universal testing machine, hammer test 


\section{PENDAhULUAN}

Beton adalah material komposit yang tersusun dari tiga penyusun utama yaitu: semen, agregat, dan air, dimana beton mempunyai kuat tekan yang besar, sementara kuat tariknya yang kecil. Tetapi sebelum material beton mengeras, campuran beton merupakan campuran yang plastis, sehingga keadaan ini sering kita sebut kelecakan beton. Sehingga, kekuatan tekan merupakan salah satu kinerja utama beton. Kekuatan tekan $\left(f^{\prime} c\right)$ adalah kemampuan beton untuk menerima gaya tekan per-satuan luas. Kuat tekan beton adalah salah satu parameter yang digunakan untuk mengontrol mutu dari sebuah beton.

Metode pengujian kuat tekan beton yang dianggap tingkat keandalannya paling tinggi adalah pengujian merusak (destructive test) dengan menggunakan alat Compression Machine. Uji merusak ini dilakukan di laboratorium dengan menguji sejumlah sampel penelitian untuk melihat capaian nilai kuat tekannya. Pengujian ini membutuhkan biaya yang cukup tinggi dan memerlukan waktu pengerjaan yang lebih lama. Namun, terkadang pengujian untuk mengetahui kuat tekan beton bisa dilakukan dengan alat non destruktif.

Pengujian ini dikenal dengan istilah uji tidak merusak (non-destructive test). Salah satu alat yang paling umum digunakan untuk metode tidak merusak ini adalah Hammer Test. Metode uji non-destructive dengan hammer test dilakukan dengan memberikan inpact (tumbukan) pada permukaan beton dengan menggunakan suatu massa yang diaktifkan dengan menggunakan energi yang besarnya tertentu. Jarak pantulan yang timbul dari massa tersebut pada saat terjadi tumbukan dengan permukaan beton benda uji dapat memberikan indikasi kuat tekan beton. Namun metode dengan menggunakan hammer test ini memiliki beberapa kekurangan diantaranya; hasil pengujian dipengaruhi oleh kerataan permukaan, kelembaban beton, sifat-sifat dan jenis agregat kasar, derajad karbonisasi dan umur beton, oleh karena itu perlu diingat bahwa beton yang akan diuji haruslah dari jenis dan kondisi yang sama.

Sebagai upaya melihat ketepatan nilai kuat tekan dari hammer test dalam penggunaan untuk kegiatan pengabdian masyarakat, maka dibuat penelitian untuk menganalisis perbandingan nilai kuat tekan betonantara metode destructive testing dan non-destructive test.

Ouput utama yang diharapkan dari penelitian ini adalah didapatkannya "konstanta pengali" untuk hammer test, dimana nilai hasil pengukurannya nanti bisa mendekati nilai dari hasil pengujian dengan menggunakan compression Machine

\section{METODE KEGIATAN}

\section{A. Metode Penelitian}

Penelitian yang bersifat eksperimental ini dilakukan di Laboratorium Struktur dan Bahan Konstruksi Jurusan Sipil Fakultas Teknik Universitas Brawijaya Malang

\section{B. Metode Pengumpulan Data}

Penelitian ini berdasarkan eksperimental dimana data-data yang di dapatkan merupakan hasil dari pelaksanaan pengujian dengan prosedur pelaksanaan sebagai berikut : 
○ Berdasarkan SNI 03-4430-1997, tentang metode pengujian elemen struktur beton dengan alat palu beton (Hammer Test) tipe $\mathrm{N}$ dan NR, dimana pengujian elemen struktur dengan alat palu beton tipe $\mathrm{N}$ dan $\mathrm{NR}$ ini dimaksudkan sebagai acuan dan pegangan dalam melaksanakan uji kekerasan permukaan beton.

○ Berdasarkan SNI 1974-1990 tentang Tata cara metode kuat tekan beton, dimana variabilitas karakteristik dan setiap bahan penyusun dalam beton dapat menyebabkan variasi kekuatan dalam beton. Demikian pula cara pembuatan benda uji, sangat berpengaruh terhadap kuat tekan mutu yang dihasilkan.

\section{Metode Pengujian}

Metode pengujian dalam rangka mencari nilai kekuatan tekan beton pada penelitian ini terbagi dua, yaitu pengujian dengan cara merusak (destructive test) dengan menggunakan Compression machine dan pengujian dengan cara tidak merusak (non destructive test) dengan menggunakan hammer Test.

Setiap benda uji yang akan dilakukan pengujian secara destructive sebelumnya dilakukan pengujian secara non destructive. Kemudian dilakukan tabulasi terhadap setiap hasil pengujian. Gambar 1 . Menunjukkan sampel benda uji yang telah siap diuji baik destructive test maupun non destructive test. Gambar 2 menunjukkan non destructive test pada silinder beton sebelum dilakukakn destructive test.

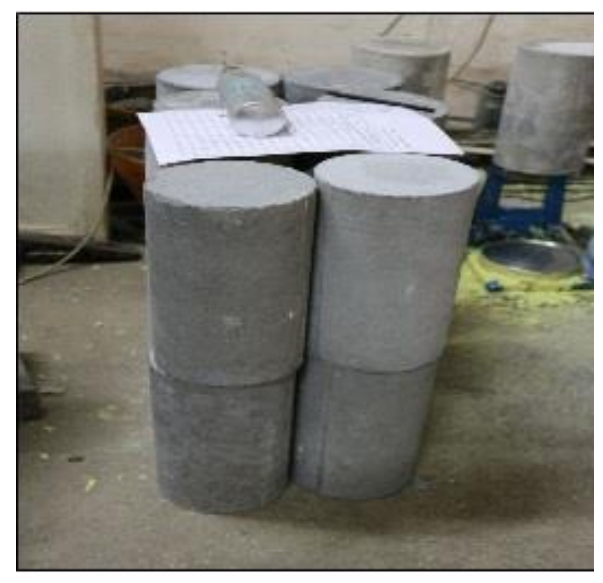

Gambar 1. Sampel beton siap uji

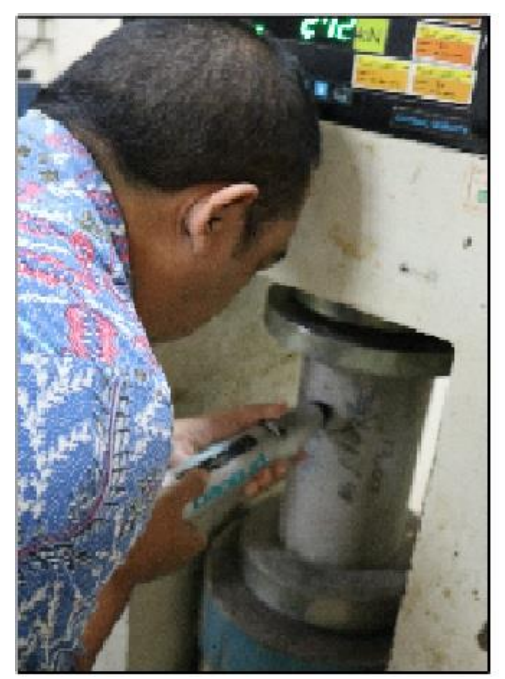

Gambar 2. Pengujian non destruktif

Destructive test untuk silinder dan kubus ditunjukkan pada Gbr. 3 dan Gbr. 4.

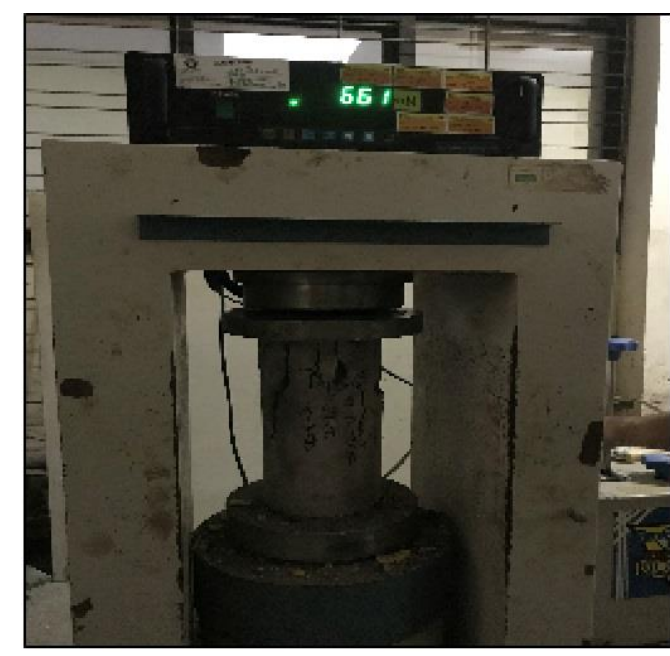

Gambar 3. Pengujian Destruktif Silinder 
Jurnal Aplikasi Sains dan Teknologi - JAST, Volume 2, Nomor 1, Januari - Juni 2018, e-ISSN 2548-7981

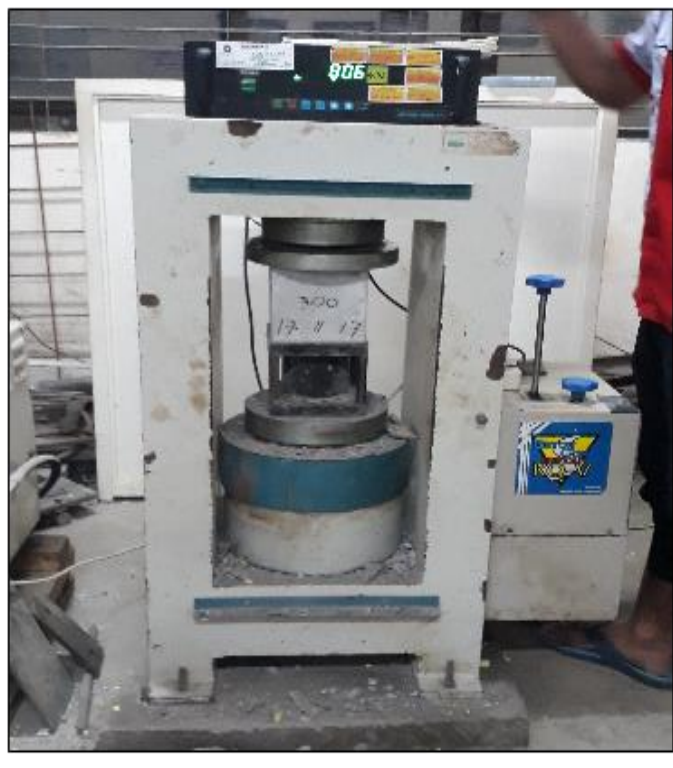

Gambar 3. Pengujian Destruktif Kubus

\section{HASIL PENGUJIAN dan PEMBAHASAN}

Dari 20 benda uji silinder dan 20 benda uji kubus yang dilakukan pengujian baik secara destruktif maupun non destruktif didapatkan nilai kekuatan tekan pada beton. Tabel 1 menunjukkan besar kuat tekan beton berdasarkan pengujian destruktrif, Tabel 2 menunjukkan perbandingan kekuatan tekan beton ratarata berdasarkan pengujian destruktif maupun non destruktif.

Tabel 1. Kekuatan Tekan beton umur 28 hari dengan pengujian destruktif

\begin{tabular}{|c|c|c|}
\hline \multirow{2}{*}{$\begin{array}{c}\text { No } \\
\text { benda } \\
\text { uji }\end{array}$} & \multicolumn{2}{|c|}{$\begin{array}{c}\text { Kuat Tekan Beton (MPa) } \\
\text { Metode Destruktif Test }\end{array}$} \\
\cline { 2 - 3 } & Silinder Beton & Kubus Beton \\
\hline 1 & 34.52 & 31.73 \\
2 & 36.67 & 34.80 \\
3 & 35.31 & 34.13 \\
4 & 34.52 & 34.67 \\
5 & 35.54 & 35.82 \\
6 & 34.41 & 33.38 \\
7 & 34.52 & 33.56 \\
8 & 37.40 & 34.13 \\
\hline
\end{tabular}

\begin{tabular}{|c|c|c|}
\hline 9 & 35.37 & 31.78 \\
10 & 36.22 & 32.22 \\
11 & 38.48 & 32.27 \\
12 & 36.10 & 31.02 \\
13 & 36.73 & 28.80 \\
14 & 36.61 & 28.98 \\
15 & 40.46 & 29.96 \\
16 & 35.08 & 30.89 \\
17 & 37.69 & 31.78 \\
18 & 35.25 & 33.38 \\
19 & 36.27 & 32.98 \\
20 & 36.90 & 31.82 \\
\hline
\end{tabular}

Tabel 2. Perbandingan Kekuatan Beton rata-rata

\begin{tabular}{|c|c|c|c|c|}
\hline \multirow{2}{*}{$\begin{array}{c}\text { Umur } \\
\text { Beton }\end{array}$} & \multicolumn{2}{|c|}{ Kuat Tekan Beton (MPa) } \\
\cline { 2 - 5 } (hari) & \multicolumn{2}{|c|}{$\begin{array}{c}\text { Metode } \\
\text { Destruktif Test }\end{array}$} & \multicolumn{2}{c|}{$\begin{array}{c}\text { Metode non } \\
\text { Destruktif Test }\end{array}$} \\
\cline { 2 - 5 } & $\begin{array}{c}\text { Silinder } \\
\text { Beton }\end{array}$ & $\begin{array}{c}\text { Kubus } \\
\text { Beton }\end{array}$ & $\begin{array}{c}\text { Silinder } \\
\text { Beton }\end{array}$ & $\begin{array}{c}\text { Kubus } \\
\text { Beton }\end{array}$ \\
\hline$>28$ & 36.2 & 32.4 & 30.8 & 29.6 \\
\hline & \multicolumn{2}{|c|}{34.3} & \multicolumn{2}{|c|}{30.2} \\
\hline
\end{tabular}

Dari perbandingan nilai kuat tekan dalam pengujian destruktif untuk beton silinder maupun kubus didapatkan hasil yang lebih besar daripada nilai kuat tekan beton dengan pengujian non destruktif. Hal ini kemudian ditunjukkan dengan prosentase nilai kuat tekan dalam pengujian destruktif dinyatakan dalam $100 \%$ maka pengujian non destruktif menunjukkan hasil kurang dari $100 \%$, seperti yang ditunjukkan pada Tabel.2.

Tabel 2. Koefisien Koreksi

\begin{tabular}{|c|c|c|}
\hline \multicolumn{3}{|c|}{ Koefisien Koreksi } \\
\hline $\begin{array}{c}\text { Silinder } \\
\text { Beton }\end{array}$ & $\begin{array}{c}\text { Kubus } \\
\text { Beton }\end{array}$ & Rata Rata \\
\hline 0.85 & 0.91 & 0.88 \\
\hline
\end{tabular}


Dari masing-masing pengujian non destruktif nilai prosentase kuat tekan dari kubus beton masih lebih besar daripada prosentase kuat tekan silinder beton jika dibandingan dengan nilai rata-rata kuat tekan dengan pengujian destruktif. Selain itu kedua nilai kuat tekan baik benda uji silinder beton maupun kubus beton dalam pengujian non destruktif lebih kecil daripada nilai kuat tekan beton dengan pengujian destruktif. Dalam penelitian ini faktor yang didapatkan antara pengujian non destruktif dengan pengujian destruktif adalah $88 \%$. Prosentase nilai tersebut jika dalam persyaratan pengujian kuat tekan beton untuk pengujian non destruktif harus melebihi $80 \%$ dari kuat tekan beton rata-rata rencana.

\section{KESIMPULAN}

Dari data pengujian diatas dapat disimpulkan bahwa dalam kegiatan pengabdian masyarakat di laboratorium Struktur Jurusan Teknik Sipil Universitas Brawijaya, metode Destruktif mempunyai kekuatan lebih tinggi dibanding non destruktif.
Pengujian non destruktif memiliki angka koreksi 0.88 terhadap pengujian destruktif, dengan kata lain pengujian non destruktif telah menunjukkan $88 \%$ kekuatan dari kuat rencana. Sehingga kuat tekan beton masih dapat diterima (memenuhi syarat).

\section{DAFTAR PUSTAKA}

[1] Lubis M, (2003), Pengujian Struktur Beton Dengan Metode Hammer Test Dan Metode Uji Pembebanan (Load Test), Digitized by USU digital library.

[2] Nurudin et.al (2015), Analisis perbandingan Nilai Kuat Tekan Beton antara Destruktif test dan non destruktif test dalam perawatan basah dan kering, Temu ilmiah IPLBI 2015

[3] SNI,tentang Metode pengujian elemen struktur beton dengan alat palu beton tipe $\mathrm{N}$ dan NR. 03-4430- 1997

[4] SNI, tentang Tata cara pengujian kuat tekan beton. SNI 1974-1990 